\title{
Seasonal wing dimorphism and life cycle of the mole cricket Gryllotalpa orientalis (Orthoptera: Gryllotalpidae)
}

\author{
CHIHIRo ENDO \\ Department of Zoology, Graduate School of Science, Kyoto University, Sakyo, Kyoto 606-8502, Japan; \\ e-mail endo@ecol.zool.kyoto-u.ac.jp
}

Key words. Gryllotalpidae, mole cricket, wing dimorphism, flightlessness, life cycle, voltinism, seasonal morph, Gryllotalpa orientalis

\begin{abstract}
Control of seasonal wing dimorphism in the oriental mole cricket Gryllotalpa orientalis Brumeister (1839) from a wetland habitat in western Japan is described. The long-winged (LW) morph appeared from mid-June to September, whereas the shortwinged (SW) morph appeared from September to mid-June. Individuals overwintered in either the adult or juvenile stage. The seasonal shift in wing morphology was linked to the overwintering stage. Individuals that hatched in May became SW adults in September-October and then overwintered, whereas those that hatched in June and July overwintered as juveniles and became LW adults in June of the following year. The life cycle of both morphs was univoltine. Reproductive benefits and constraints of each wing morph of $G$. orientalis are compared.
\end{abstract}

\section{INTRODUCTION}

In many pterygote insects, wing polymorphism, i.e., the presence of macropterous (long-winged) individuals and obligate flightless (wingless or with reduced wings) individuals, has been classified as a type of dispersal polymorphism (Harrison, 1980; Roff, 1986; Zera \& Denno, 1997). When the population density is low and competition for food and mates is not severe, individuals do not need to disperse and short-winged (SW) or wingless morphs would be favoured. In contrast, when the population density is high and the competition is severe, the long-winged (LW) morph, which can disperse to a better habitat, would be favoured.

Seasonal wing polymorphism has been found in organisms with multivoltine life cycles, and the favoured morph differs between the first and second or later generations (e.g., Harada, 1996; Van Dyck \& Wiklund, 2002; Olvido et al., 2003). In seasonal polymorphism, the selection pressure varies seasonally, and the favoured morph is fixed for each season. When two or more morphs are present simultaneously, each morph simultaneously or alternately confer advantage. Thus, it is important to determine how wing polymorphism is maintained in the life cycles to understand why it is maintained.

Although wing polymorphism is found in many cricket species (Masaki \& Walker, 1987), wing polymorphism in mole crickets has not previously been reported. Mole crickets are adapted to life underground; thus, direct observation is difficult and details of their ecology remain unknown in most species. Males call from burrows at night to attract mates and conspecific females fly to the burrows of males (Ulagaraj, 1975; Forrest, 1983). Females fly to search effectively for mates and to move to new habitats for oviposition or feeding. Males can also fly and are attracted to the songs of conspecific males, as well as females (Walker, 1982). The short-winged mole cricket Scapteriscus abbreviatus Scudder is a flightless species, whereas the northern mole cricket Neocurtilla hexadactyla Party shows geographic variation in flightless morph (Hayslip, 1943; Semlitsch, 1986; Capinera et al., 2005); nonetheless, flightlessness in mole crickets has received little attention. Light traps and sound traps that play back the conspecific male song (Walker, 1982) are effective methods for collecting mole crickets; however, they only attract flying mole crickets. Thus, the basic life cycle of mole crickets will only be elucidated by performing seasonal soil excavations.

Seasonal wing dimorphism in a local population of the oriental mole cricket Gryllotalpa orientalis (Orthoptera: Gryllotalpidae) is presented. The seasonal emergence pattern and life cycle of each morph of this species is documented and the reproductive benefits and constraints of each wing morph compared. Questions regarding whether the seasonal shift in wing morph is generally related to the voltinism and whether this pattern of alternating wing length with the life cycle occurs in other species of mole cricket are considered.

\section{MATERIAL AND METHODS}

\section{Study species}

The oriental mole cricket Gryllotalpa orientalis Brumeister (Orthoptera: Gryllotalpidae) is widely distributed across Japan, China, the Korean Peninsula, and Taiwan. Populations in Japan were long regarded as $G$. africana, but are now assigned to $G$. orientalis (Townsend, 1983). Juveniles moult eight times during development (Sakurai et al., 1960). As juveniles do not develop wing buds before the seventh stage (instar), the wing morph of early instars cannot be determined in the field. Seventh instars have small wing buds, whereas eighth instars have large wing buds. Adults have complete wings and the sexes can be distinguished by the presence of a stridulating organ and pattern of venation in the forewings. 


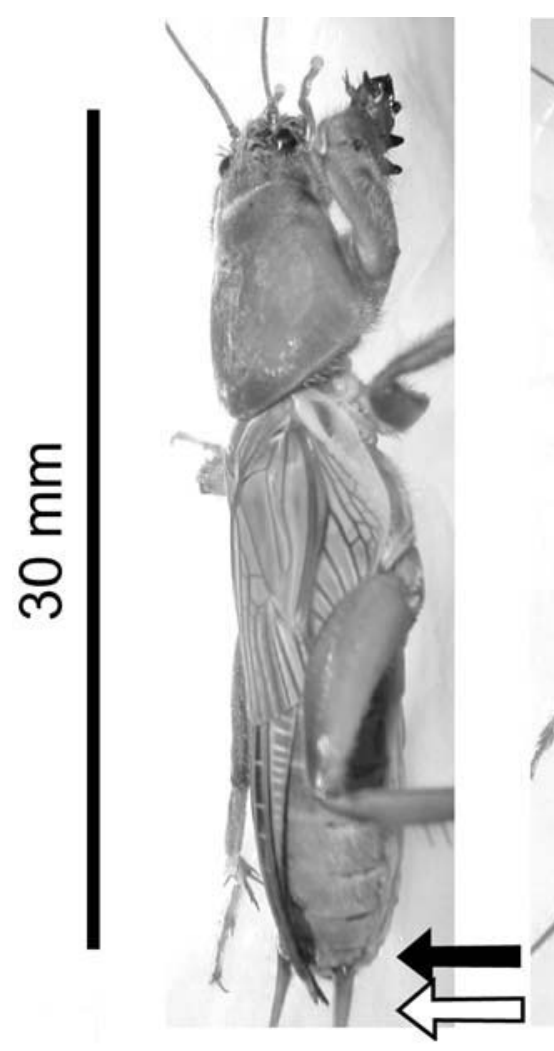

a

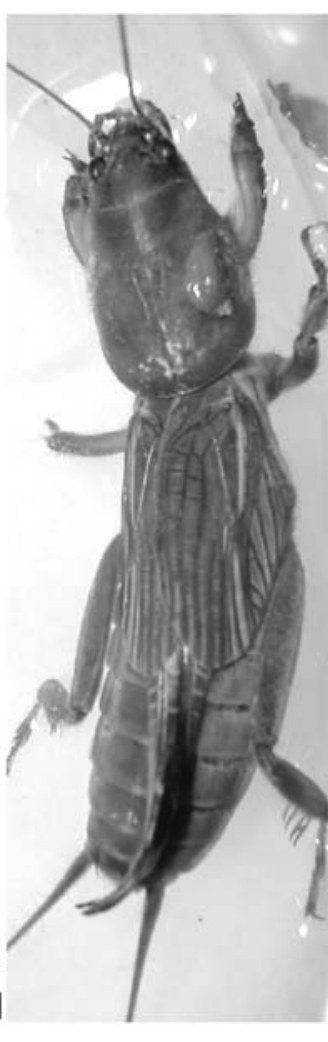

b

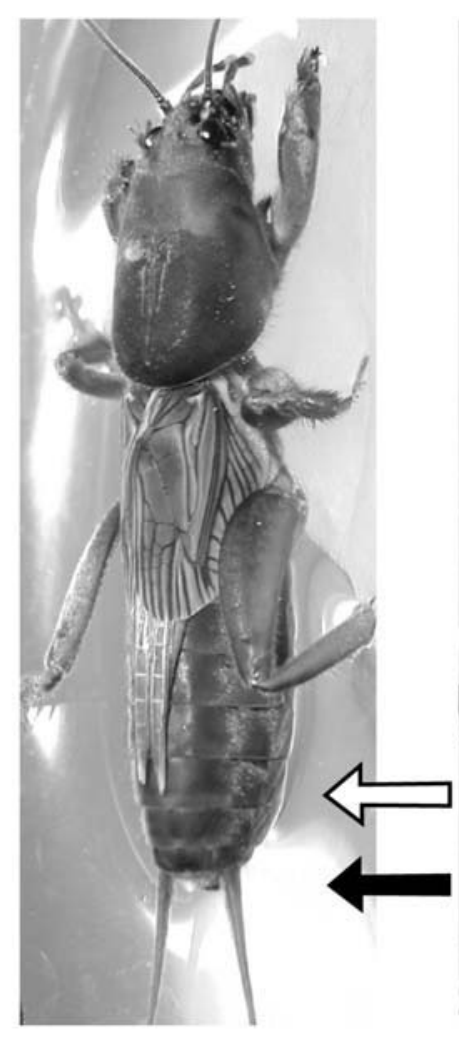

C

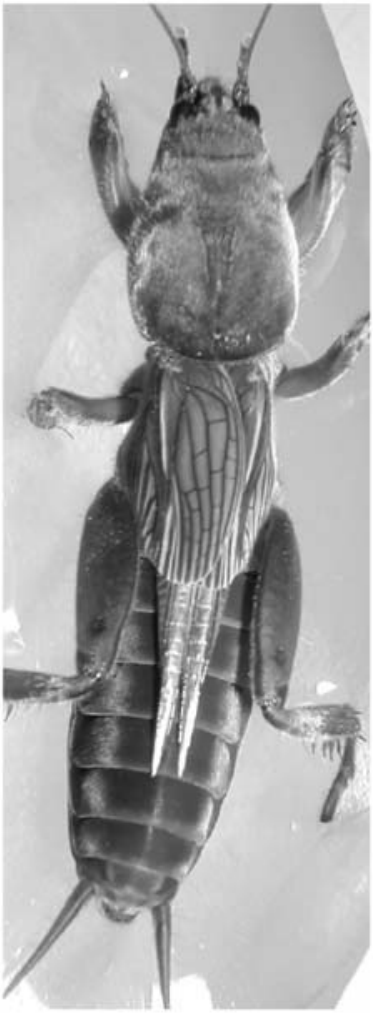

d

Fig. 1. Long winged (LW) morph and short winged (SW) morph. a - LW male, b-LW female, $c-S W$ male, $d-S W$ female. A black arrow indicates abdomen and a white arrow indicates tips of hindwing.

\section{Study site}

The study site was a wetland area in the Hyogo Prefectural Homeland for the Oriental White Stork $\left(35^{\circ} 35^{\prime} \mathrm{N}, 134^{\circ} 51^{\prime} \mathrm{E}\right)$, Toyo-oka, western Japan. This wetland area was located in a valley and was surrounded by woodlands consisting of temperate deciduous forest and broadleaf evergreen forest. Many paddy fields were located outside the wetland. The area receives snow from December to February.

\section{Sampling methods}

Mole crickets were sampled regularly for approximately four days each month from March to November in 2002 and 2003 and from March to October in 2004. On each sampling day, several $50 \times 50 \mathrm{~cm}$ quadrats were placed in the wetland and the soil within each quadrat excavated to a depth of approximately 20 $\mathrm{cm}$ to collect all mole crickets. The mean area excavated each month was $3.32( \pm 2.41 \mathrm{SD}) \mathrm{m}^{2}$. Areas were selected for excavation based on the presence of signs of tunnelling or feeding by mole crickets. For areas that were too small to fit the standard quadrat, the area was measured after excavation. Mole crickets oviposit a clutch of eggs in an egg chamber. When an egg chamber was found during soil excavation, the number of eggs was counted.

To collect flying adults, a light trap and sound traps were deployed for three to four nights each month from June to October 2003 and from April to October 2004. One light trap was set beside the wetland and four to five sound traps were set at intervals of about $50 \mathrm{~m}$ along the Kamatani River. The light trap consisted of an ultraviolet fluorescent light $(15 \mathrm{~W}, 300-400$ $\mathrm{nm}$ wavelength) reflected on to white cloth $(100 \times 200 \mathrm{~cm})$ at a height of $100 \mathrm{~cm}$. A funnel $(100 \mathrm{~cm}$ in diameter $)$ connected to a plastic bucket ( $25 \mathrm{~cm}$ in diameter, $40 \mathrm{~cm}$ deep) containing water was placed under the light to capture the attracted insects. The light trap was set for about $10 \mathrm{~h}$ from after sunset to dawn. Sound traps were constructed according to Walker (1982). A speaker (Panasonic, RP-SP30K) was connected to a portable CD player (FISHER, Z-ACDP1[S]). The speaker was sealed in waterproof wrapping and placed in a plastic bucket $(45 \mathrm{~cm}$ in diameter, $20 \mathrm{~cm}$ deep) filled with water. The $\mathrm{CD}$ player was placed in a plastic case outside the bucket. A series of male calls from the same population recorded in May 2002 at Toyo-oka was used as the sound source. The sound was played for five $h$ beginning after sunset, which corresponds to the natural calling time of males. The plastic buckets trap only flying insects because insects could not climb the outer walls. Trapped mole crickets were collected the following morning. In total, the light trap was active for 18 nights in 2003 and 19 nights in 2004, and the sound traps were active for 19 nights in 2003 and 28 nights in 2004.

For mole crickets collected from soil excavations and traps, the pronotum width and forewing and hindwing length were measured to the nearest $0.01 \mathrm{~mm}$ using calipers. Pronotum width is an index of body size. According to Walker and Sivinski (1986), the ratio of hindwing (HW) to forewing (FW) length is used to discriminate among wing morphs. Several females collected each month were dissected to determine whether the ovaries were mature and whether there was sperm in the spermatheca. The wet mass of sperm in the spermatheca was measured using an electric balance (Sartorius BP210D). Presence of corpus luteum in the ovaries was regarded as evidence of oviposition. The remaining crickets were released in the wetland after measurement. 

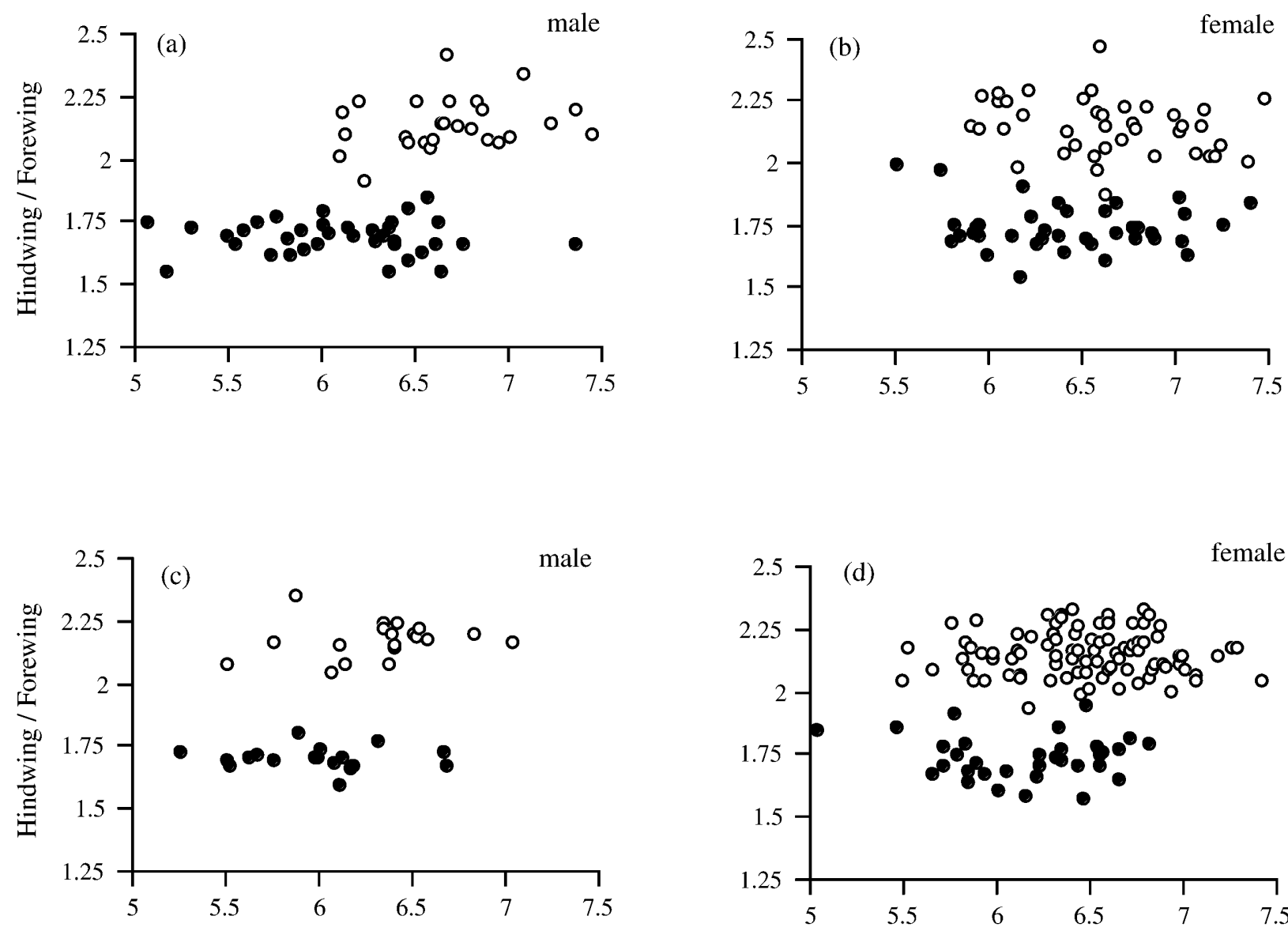

Pronotum width (mm)

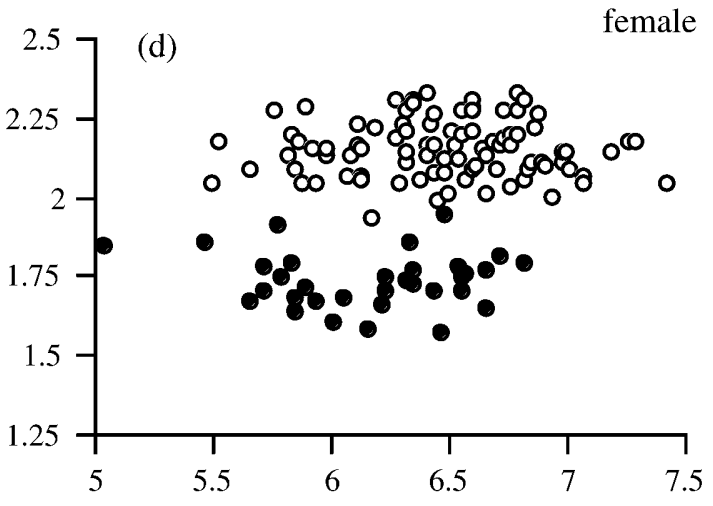

Pronotum width (mm)

Fig. 2. Relationship between HW/FW ratio and pronotum width of males and females in 2003 (a, b) and 2004 (c, d) (black circle: SW, white circle: LW).

\section{Data analysis}

Adult wing ratio $(\mathrm{HW} / \mathrm{FW})$ was compared in each sex using analysis of covariance (ANCOVA) with wing morph as the factor and pronotum size as the covariate. Juvenile wing ratio was compared between individuals in spring and autumn using ANCOVA with season as the factor and pronotum size as the covariate for seventh and eighth instars. One-way ANOVA was used to compare the number of eggs found in egg chambers among months. A Mann-Whitney U-test was used to detect differences between wing morphs in the number of eggs per egg chamber.

\section{RESULTS}

\section{Wing length}

Adults collected during soil excavations and in traps were divided into long-winged (LW) and short-winged (SW) morphs according to forewing and hindwing lengths. The hindwings of LW individuals covered the abdomen, whereas the hindwings of SW individuals did not (Fig. 1).

Irrespective of pronotum width, there were two groups with significantly different $\mathrm{HW} / \mathrm{FW}$ ratios for both males and females in 2003 (ANCOVA, male: $\mathrm{F}_{1,61}=286.8, \mathrm{P}<$ 0.0001; female: $\left.\mathrm{F}_{1,78}=295.5, \mathrm{P}<0.0001\right)$ and 2004 (male: $\mathrm{F}_{1,34}=436.5, \mathrm{P}<0.0001$; female: $\mathrm{F}_{1,121}=487.1, \mathrm{P}$
$<0.0001$; Fig. 2). In 2002, the sample size was too small to perform the analysis.

\section{Wing morph and life cycle}

Seasonal changes in the size distribution of mole crickets in 2002 and 2003 are shown in Fig. 3; this same trend was observed in 2004. Egg chambers with eggs were discovered mainly from April to June and in small numbers in July, but few egg chambers were found in June 2003. Newly hatched juveniles appeared from May - June. In November, juveniles and SW adults were found, both of which overwintered. In March, overwintering juveniles and SW adults were observed. In November and March, neither juveniles $<3 \mathrm{~mm}$ in pronotum width, nor seventh and eighth instars were found (Fig. 3). Eighth instars became adult in either June or September-October. The calling period was from April to October.

The LW morph (individuals with hindwings $>20 \mathrm{~mm}$ ) was only observed from June to September (Fig. 4). Concomitantly, mole crickets were only caught in traps between June and September. SW morphs were never found in traps. The percentage of LW morph individuals found in soil excavations for males and females was $15 \%$ $(\mathrm{n}=34)$ and $10 \%(\mathrm{n}=41)$ respectively in $2002,9.8 \%(\mathrm{n}$ 
(a) 2002

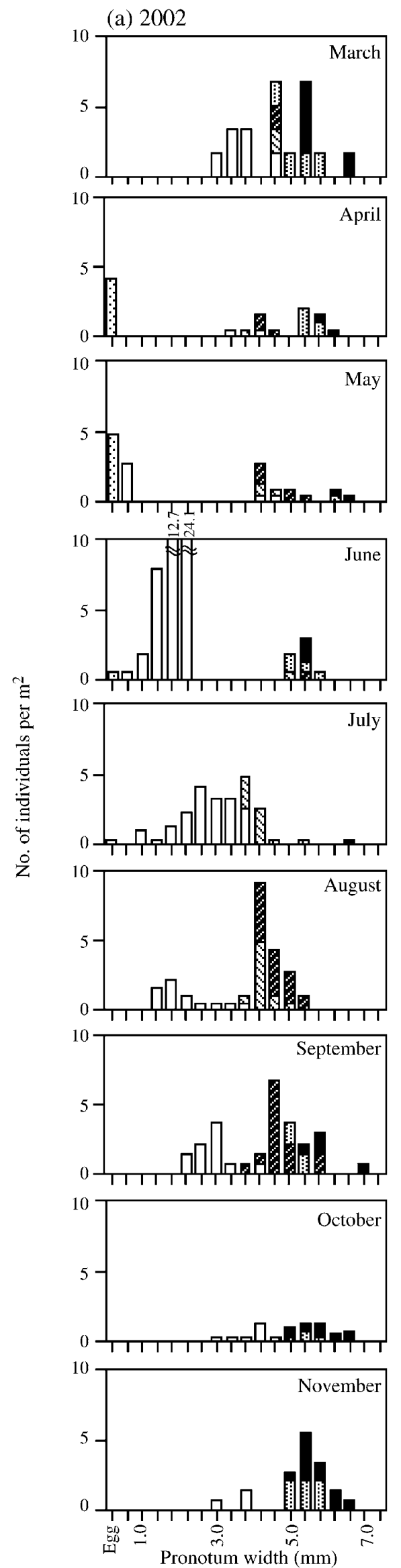

(b) 2003

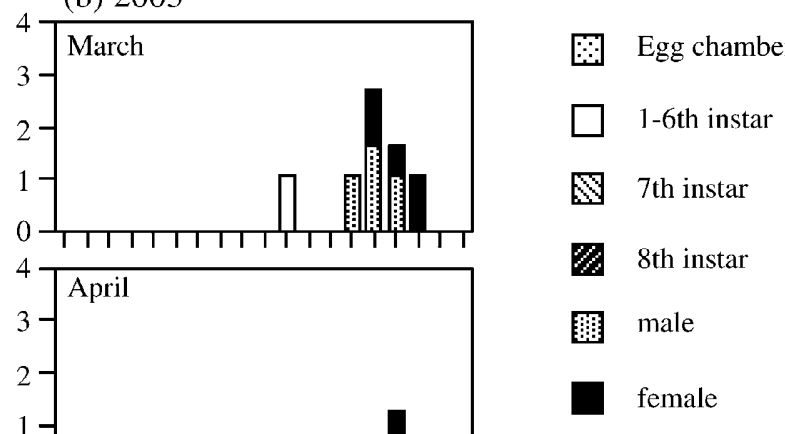

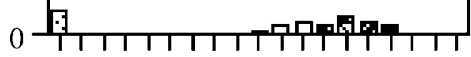
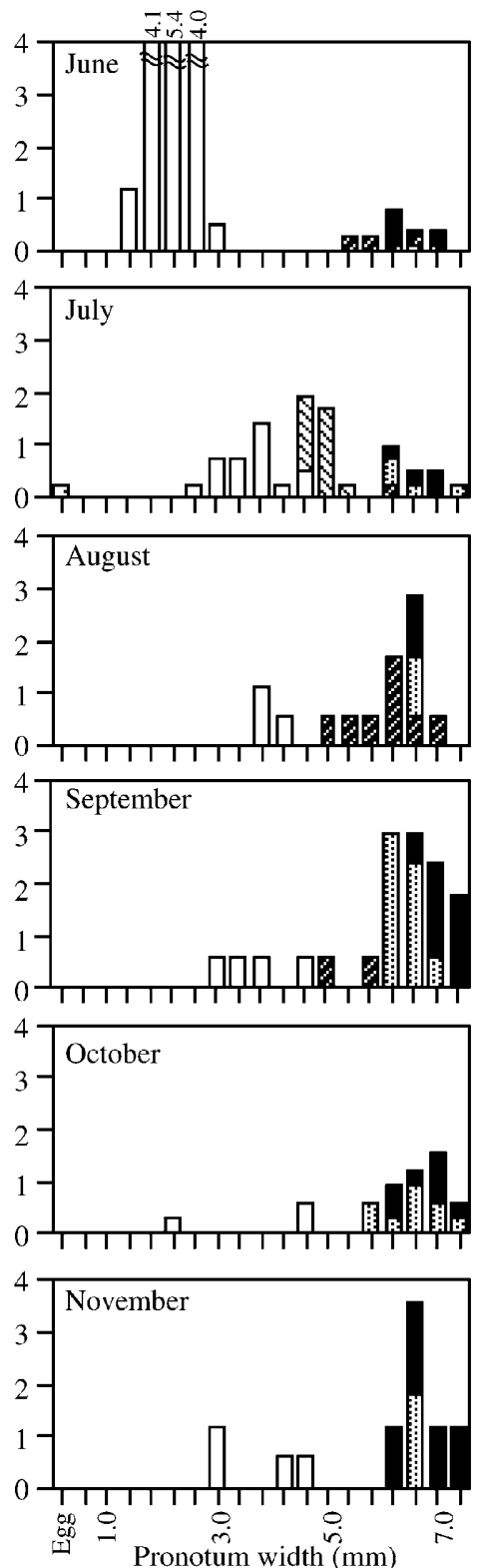

Fig. 3. Seasonal size distribution of mole crickets collected in $1 \mathrm{~m}^{2}$ in 2002 (a) and 2003 (b). Pronotum width was used as an indicator of body size. Numbers of egg chambers are shown by the leftmost column. 
TABLE 1. Seasonal change in reproductive condition of females of each wing morph.

\begin{tabular}{|c|c|c|c|c|c|c|c|c|}
\hline Wing morph & & Apr. & May & Jun. & Jul. & Aug. & Sep. & Oct. \\
\hline \multicolumn{9}{|l|}{ SW female } \\
\hline & percent of mature eggs present & 100 & 91.7 & 100 & - & - & 0 & 0 \\
\hline & (n) & $(12 / 12)$ & $(11 / 12)$ & $(7 / 7)$ & & & $(0 / 1)$ & $(0 / 2)$ \\
\hline & percent of sperm present in spermatheca & 100 & 91.7 & 100 & - & - & 0 & 100 \\
\hline & (n) & $(12 / 12)$ & $(11 / 12)$ & $(7 / 7)$ & & & $(0 / 1)$ & $(2 / 2)$ \\
\hline & percent of oviposited $>1$ egg clutch & 25.0 & 85.7 & 71.4 & - & - & 0 & 0 \\
\hline & (n) & $(1 / 4)$ & $(6 / 7)$ & $(5 / 7)$ & & & $(0 / 1)$ & $(0 / 2)$ \\
\hline \multicolumn{9}{|l|}{ LW female } \\
\hline & percent of mature eggs present & - & - & 44.4 & 86.7 & 75.0 & 25.0 & - \\
\hline & (n) & & & $(4 / 9)$ & $(13 / 15)$ & $(3 / 4)$ & $(1 / 4)$ & \\
\hline & percent of sperm present in spermatheca & - & - & 44.4 & 93.3 & 100 & 25.0 & - \\
\hline & (n) & & & $(4 / 9)$ & $(14 / 15)$ & $(4 / 4)$ & $(1 / 4)$ & \\
\hline & percent of oviposited $>1$ egg clutch & - & - & 11.1 & 40.0 & 0 & 25.0 & - \\
\hline & (n) & & & $(1 / 9)$ & $(6 / 15)$ & $(0 / 4)$ & $(1 / 4)$ & \\
\hline
\end{tabular}

$=41)$ and $23.1 \%(\mathrm{n}=52)$ in 2003 , and $28.0 \%(\mathrm{n}=25)$ and $17.1 \%(\mathrm{n}=41)$ in 2004 .

The proportion of mature females in each month was determined by counting the number of dissected females with eggs (Table 1). In SW females, the proportion of mature individuals was $100.0 \%$ in April, 91.7\% in May, and $100.0 \%$ in June; no SW females were mature in September and October, although the sample size was only three. In LW females, the proportion of mature indi-
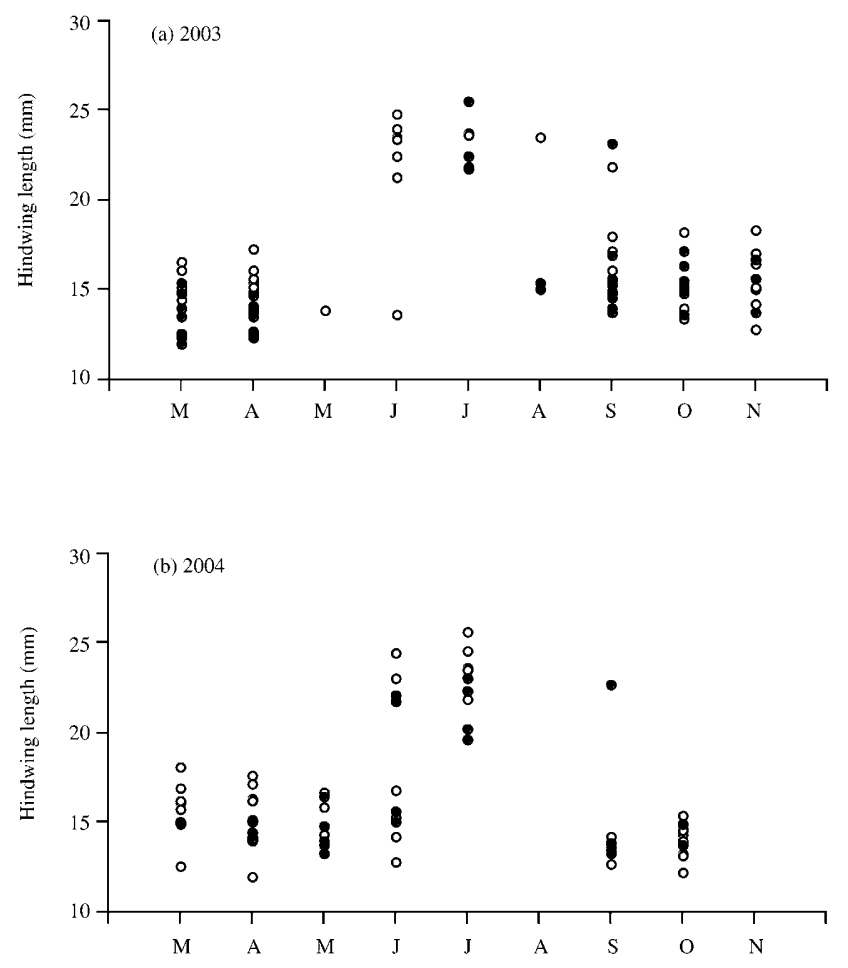

Fig. 4. Seasonal distribution of hindwing length of males (black circle) and females (white circle). Data were collected from soil excavation in 2003 (a) and 2004 (b). viduals was $44.4 \%$ in June, $86.7 \%$ in July, $75.0 \%$ in August and $25.0 \%$ in September. SW females mated in autumn and appeared to lay eggs in early April. After SW females completed oviposition, they died in May or June. LW females mated soon after the final moult, oviposited during summer and died before autumn (Table 1, Fig. 5). The mass of sperm in the spermathecae varied from 1.0 $\mathrm{mg}$ to $14.0 \mathrm{mg}$ and mean value was $5.0 \pm 1.0 \mathrm{mg}($ mean \pm S.E., $n=40)$.

For eighth instars, the HW/FW ratio was compared between individuals in spring and autumn. Irrespective of pronotum width, spring juveniles had a significantly greater $\mathrm{HW} / \mathrm{FW}$ ratio than autumn juveniles (ANCOVA, $\left.\mathrm{F}_{1,38}=12.34, \mathrm{P}<0.001\right)$. A similar trend was detected for seventh instars $\left(F_{1,32}=5.00, P=0.03\right)$. Juveniles that hatched in May appeared to grow into SW adults in September and October and overwintered; juveniles that hatched in June and July appeared to overwinter as older instars and became LW adults in early summer of the following year (Fig. 5). The wing morph shifted seasonally in this population and was linked to the overwintering stage. Both the LW and SW life cycles were univoltine.

\section{Egg numbers of each morph}

Eggs of G. orientalis were laid between April and July, few egg chambers were found in July. The number of eggs found in egg chambers was not significantly different among months (one-way ANOVA, $\mathrm{F}_{3,49}=1.01, \mathrm{P}=$ 0.40; Table 2). To compare wing morphs for the number of eggs produced, data were sorted depending on the period in which egg chambers were found. There was no difference between wing morphs in the number of eggs per egg chamber (Mann-Whitney U-test, $\mathrm{U}=122.5, \mathrm{P}=$ 0.60 ; Table 2).

\section{DISCUSSION}

In this study factors that control seasonal wing dimorphism of $G$. orientalis were not examined. Controlled 


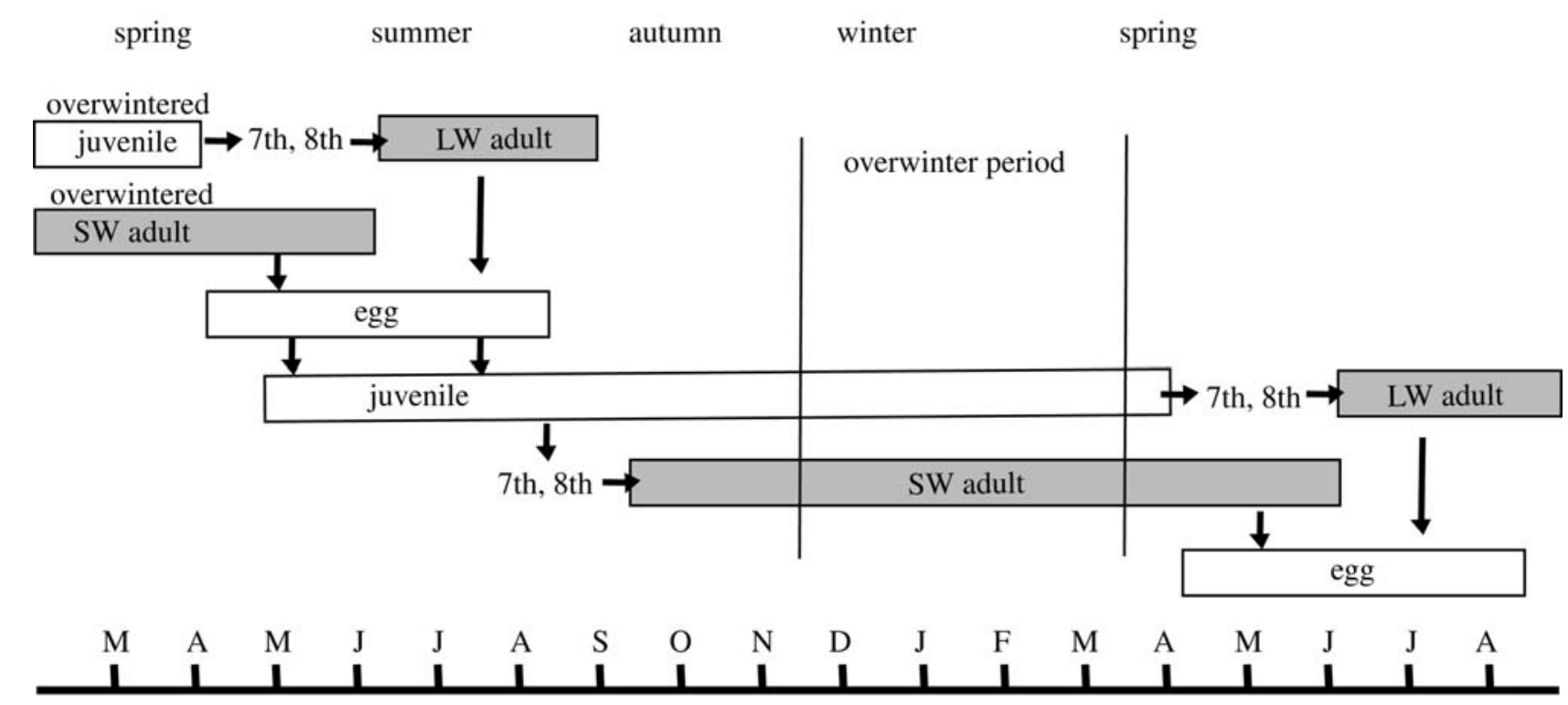

Fig. 5. Possible alternative pathways explaining seasonal wing dimorphism. The wing morph of eggs and juveniles of early developmental stages cannot be distinguished. When juveniles reach the 7th stage during summer, they become SW adults before winter. Other juveniles overwinter in the juvenile stages and become LW adults in the following summer. Seasonal wing dimorphism in $G$. orientalis is maintained in a univoltine life cycle with two different developmental pathways.

experiments are required to confirm the mechanism regulating seasonal wing dimorphism.

In $G$. orientalis, differences in wing morphology are linked to the overwintering form. Because the oviposition period ranges from April to July, juveniles reach various developmental stages before winter. Considering the seasonal wing morph pattern, it is likely that juveniles that hatch early in the reproductive period can reach later developmental stages and become SW adults before winter. In contrast, those that hatch late in the reproductive period or hatch early, but fail to forage sufficiently, cannot develop into adults before winter. These individuals would overwinter as juveniles and become LW adults in the following early summer. However, because juveniles $<3 \mathrm{~mm}$ in pronotum width were not found before or after overwintering (Fig. 3), it is likely that juveniles with poor nutrient state cannot overwinter. Seventh and eighth instars caught in April and May tend to

TABLE 2. The number of egg chambers and eggs in a chamber. Data were collected in 2002, 2003 and 2004. One-way ANOVA was used to compare the no. of eggs among each month. All egg chambers were sorted into SW and LW morph's based on the period that eggs were found. Mann-Whitney $U$-test was used to examine the difference of no. of eggs between wing morph.

\begin{tabular}{lccc}
\hline Month & $\begin{array}{c}\text { No. of egg } \\
\text { chambers }\end{array}$ & $\begin{array}{c}\text { No. of eggs } \\
\text { (mean } \pm \text { SE) }\end{array}$ & \\
\hline April & 12 & $46.9 \pm 4.66$ & $\mathrm{a}$ \\
May & 28 & $53.9 \pm 2.26$ & $\mathrm{a}$ \\
June & 10 & $50.8 \pm 4.63$ & $\mathrm{a}$ \\
July & 3 & $44.3 \pm 8.67$ & $\mathrm{a}$ \\
\hline SW (Apr.-mid Jun.) & 47 & $50.9 \pm 1.98$ & $\mathrm{~b}$ \\
LW (mid Jun.-Jul.) & 6 & $53.5 \pm 6.07$ & $\mathrm{~b}$ \\
\hline
\end{tabular}

a: $F_{3,49}=1.07, P=0.40$, One-way ANOVA

b: $P=0.60$, Mann-Whitney $U$-test have a larger $\mathrm{HW} / \mathrm{FW}$ ratio than those caught in July-September. It appears that the wing form is already determined by the time that wing buds have developed.

During autumn, SW males call for females and SW females mate (Table 1). Sperm are kept alive in the spermatheca until spring, at which time the female began to lay eggs. This was observed in a SW female $(n=1)$. Autumn mating and winter sperm storage is also reported in Scapteriscus acletus (Walker \& Nation, 1982). If mating was finished before winter, females could devote their energy to laying eggs in spring. There may be some advantage in maturing before winter for the SW morph. Variation in the mass of sperm in the spermatheca in $G$. orientalis suggests that females allocate the stored sperm to several clutches of eggs. The number of eggs in one egg chamber did not differ among morphs and there was little variance among months (Table 2). However, because the ratio of females that had oviposited at least one egg clutch tended to be higher in SW females than LW females (Table 1), SW females may oviposit more times than LW females. However, volume or mass of eggs in a clutch was not measured, and these data are required for detailed comparisons of reproductive efforts between morphs. Overwintering juveniles have a long developmental period before becoming adults and become the LW morph. Thus, the different developmental pathways are to grow as quickly as possible and become a SW morph before winter, or grow slowly and become a LW morph in the following year.

Habitat stability and quality also affect the fitness of each morph (Roff, 1986; Denno et al., 1996). Juveniles that cannot become adults before winter may consider that the habitat is of poor quality. It is reasonable that these juveniles become LW adults in the following spring to disperse to a habitat of good quality. 
On the main island of Japan, the long rainy season begins in mid-June to mid-July, changing the state of the habitat and flooding the soil in early summer. After the rainy season, the soil tends to dry during the summer drought. Seasonal changes in rainfall and soil moisture appear to affect the oviposition sites of $G$. orientalis. Most flying females that were attracted to the light trap had already mated $(85.7 \%, \mathrm{n}=14)$ but had not oviposited $(92.9 \%, n=14)$, suggesting that they were searching for a suitable oviposition site. Few egg chambers were found after mid-July. LW females may deposit eggs after July in habitats other than the wetland studied. However, late oviposition is risky because juveniles may not grow large enough to overwinter. Thus, for the LW morph, it is important to find mates efficiently and oviposit soon.

Although the timing of oviposition varies between SW and LW females, both die after oviposition. It is unlikely that LW adults overwinter, unless they hide in different habitats. No LW adults were observed to overwinter in the study area over five years.

Seasonal wing polymorphism is often accompanied by a multivoltine life cycle, e.g., butterfly Pararge aegeria (Van Dyck \& Wiklund, 2002), water strider Aquarius paludum (Harada, 1996), or southern ground cricket Allonemobius socius (Olvido et al., 2003). In $G$. orientalis, seasonal wing dimorphism is maintained in a univoltine life cycle with two different developmental processes linked to the overwintering form. In other species of mole cricket, however, the overwintering form and voltinism are not always related to wing morphology. Univoltine mole crickets in North America, such as $S$. vicinus and $S$. acletus, overwinter as either juveniles or adults and these species have only LW adults (Walker \& Fritz, 1983; Walker et al., 1983). Neocurtilla hexadactyla is semivoltine and SW in South Carolina, univoltine and SW in Florida, and univoltine and LW in the Caribbean and Central and South America (Hayslip, 1943; Semlitsch, 1986; Capinera et al., 2005).

Mole crickets tend to have a univoltine life cycle in southern areas and a semivoltine life cycle in northern areas. They overwinter either as adults or juveniles in the univoltine life cycle, and as both juveniles and adults in the semivoltine life cycle (Masaki \& Walker, 1987). Flight behaviour would be restricted to a suitable temperature range (Ulagaraj, 1975), whereas reproductive activity, such as calling, mating, and oviposition, would be less strictly restricted by temperature. In addition, temperatures inside the burrow would be relatively milder than outside. Thus, it is possible that reproductive activity in the burrow begins considerably earlier in spring than flight behaviour. Flightlessness may arise when differences in these periods of activity are very large.

$G$. orientalis has a wide distribution, so further investigation of wing morphology, with respect to the life cycle and reproductive and flight periods, in various regions (especially, comparisons between northern and southern populations) is required. Moreover, similar investigations in other species of mole cricket will help to detect the pattern of appearance of flightlessness with climate and lati- tude (e.g. Masaki, 1996). Seasonal wing dimorphism in the univoltine life cycle of $G$. orientalis occurred via two different developmental processes; these alternatives appeared to make it possible for individuals to best use the available time and space.

ACKNOWLEDGEMENTS. I appreciate H. Ikeda, Y. Osako, N. Watanabe, S. Kimura and the staff of Hyogo Prefectural Homeland for the Oriental White Stork for constant support. I thank M. Hori, T. Sota and the members of the Laboratory of Animal Ecology, Kyoto University for their critical comments and suggestions. I thank two anonymous referees for improvements of the manuscript. I also thank N. Endo for field assistance. This study was partly supported by the white stork fund of Toyo-oka city.

\section{REFERENCES}

Capinera J.L., Scott R.D. \& Walker T.J. 2005: Field Guide to Grasshoppers, Katydids, and Crickets of the United States. Cornell University Press, New York, 280 pp.

Denno R.F., Roderick G.K., Peterson M.A., Huberty A.F., Döbel H.G., Eubanks M.D., Losey J.E. \& Langellotto G.A. 1996: Habitat persistence underlies intraspecific variation in the dispersal strategies of planthoppers. Ecol. Monogr. 66: 389-408.

ForRest T.G. 1983: Calling songs and mate choice in mole crickets. In Gwynne D.T. \& Morris G.K. (eds): Orthopteran Mating Systems: Sexual Competition in a Diverse Group of Insects. Westview Press, Boulder, Colorado, pp. 185-204.

HARADA T. 1996: Life history strategies of Japanese striders showing wing polymorphism. The Insectarium 33: 264-271. [in Japanese].

HARRISON R.G. 1980: Dispersal polymorphism in insects. Annu. Rev. Ecol. Evol. Syst. 11: 95-118.

HAYSLIP N.C. 1943: Notes on biological studies of mole crickets at Plant city, Florida. Fla. Entomol. 3: 33-46.

MASAKI S. 1996: Geographical variation of life cycle in crickets (Ensifera: Grylloidae). Eur. J. Entomol. 93: 281-302.

Masaki S. \& Walker T.J. 1987: Cricket life cycles. In Hecht M.K., Wallace B. \& Prance G.T. (eds): Series: Evolutionary Biology 21. Plenum, New York, pp. 349-423.

Olvido A.E., Elvington E.S. \& Mousseau T.A. 2003: Relative effects of climate and crowding on wing polymorphism in the southern ground cricket, Allonemobius socius (Orthoptera: Gryllidae). Fla. Entomol. 86: 158-164.

RofF D.A. 1986: The evolution of wing dimorphism in insects. Evolution 40: 1009-1020.

Sakurai K., Tsutsumi M. \& Hotta Y. 1960: Potato pest insect, mole cricket and the control method. Hokunou 22: 157-167. [in Japanese].

SemLitsch R.D. 1986: Life history of the northern mole cricket, Neocurtilla hexadactyla (Orthoptera:Gryllotalpidae), utilizing Carolina-bay habitats. Ann. Entomol. Soc. Am. 79: 256-261.

Townsend B.C. 1983: A revision of the Afrotropical molecrickets (Orthoptera: Gryllotalpidae). Bull. Br. Mus. Nat. Hist. (Entomol.) 42: 175-203.

Ulagaraj S.M. 1975: Mole crickets: Ecology, behavior, and dispersal flight (Orthoptera: Gryllotalpidae, Scapteriscus). Environ. Entomol. 4: 299-306.

VAN Dyck H. \& WikLund C. 2002: Seasonal butterfly design: morphological plasticity among three developmental pathways relative to sex, flight and thermoregulation. J. Evol. Biol. 15: 216-225. 
WALKer T.J. 1982: Sound traps for sampling mole cricket flights (Orthoptera: Gryllotalpidae: Scapteriscus). Fla. Entomol. 65: 105-110.

Walker T.J. \& Nation J.L. 1982: Sperm storage in mole crickets: fall matings fertilize spring eggs in Scapteriscus acletus. Fla. Entomol. 65: 283-285.

WALKER T.J. \& Fritz G.N. 1983: Migratory and local flights in mole crickets, Scapteriscus acletus and S. vicinus. Environ. Entomol. 12: 953-958.
WalKer T.J. \& Sivinski J.M. 1986: Wing dimorphism in field crickets (Orthoptera: Gryllidae: Gryllus). Ann. Entomol. Soc. Am. 79: 84-90.

Walker T.J., Reinert J.A. \& Schuster D.J. 1983: Geographical variation in flights of the mole cricket, Scapteriscus spp. (Orthoptera: Gryllotalpidae). Ann. Entomol. Soc. Am. 76: 507-517.

Zera A.J. \& Denno R.F. 1997: Physiology and ecology of dispersal polymorphism in insects. Annu. Rev. Entomol. 42: 207-230.

Received March 8, 2006; revised and accepted June 7, 2006 